\title{
KEANEKARAGAMAN ACARINA DI PUSAT INOVASI AGRO TEKNOLOGI MANGUNAN
}

\section{(THE DIVERSITY OF ACARINA IN AGRO TECHNOLOGY INNOVATION CENTER MANGUNAN)}

\author{
Soenarwan Hery Poerwanto, Anggun Handiani, dan Dila Hening Windyaraini \\ Fakultas Biologi Universitas Gadjah Mada Yogyakarta \\ Jl. Teknika Selatan, Sekip Utara, Yogyakarta 55281 \\ email: soenarwan@ugm.ac.id
}

\begin{abstract}
Abstrak
Penelitian ini dilakukan untuk mengetahui keanekaragaman Acarina dan faktor lingkungan yang mempengaruhi keberadaan Acarina di Pusat Inovasi Agro Teknologi (PIAT) Mangunan, Yogyakarta. Penelitian ini dilakukan di PIAT Mangunan untuk pengambilan sampel dan Laboratorium Sistematika Hewan bagian Parasitologi Fakultas Biologi UGM untuk preparasi dan identifikasi. Metode yang digunakan adalah ekstraksi sampel menggunakan corong Barlese Tullgren dengan beberapa modifikasi. Sampel diambil pada 3 area vegetasi (sirsak, srikaya, dan sawo) dan setiap area diambil lima titik sampling. Pengukuran lingkungan meliputi kelembaban udara dan suhu udara diukur dengan alat higrometer, $\mathrm{pH}$, dan suhu tanah dengan soil tester digital, serta kelembaban tanah dengan soil tester Takemura DM-5. Acarina yang diperoleh dilihat di bawah mikroskop dan di-mounting dengan larutan hoyer's. Identifikasi Acarina menggunakan buku identifikasi A Manual of Acarology. Data yang diperoleh dari penelitian dianalisis menggunakan indeks keanekaragaman Shannon-Wiener. Berdasarkan identifikasi Acarina yang telah dilakukan, didapatkan 20 Family dan 28 Genus dan 399 cacah individu. Tingkat keanekaragaman Acarina termasuk dalam kategori sedang. Faktor lingkungan yang mempengaruhi kehadiran Acarina adalah suhu dan kelembaban.
\end{abstract}

Kata kunci: Acarina, Barlese Tullgren, Shannon-Wiener

\begin{abstract}
This study was aimed at determining the diversity of Acarina and environmental factors that affect the existence Acarina at Agro Technology Innovation Center (ATIC) Mangunan, Yogyakarta. This study was conducting at ATIC Mangunan for sampling and the Animal Systematics Laboratory of the Parasitology, Faculty of Biology, Gajah Mada University for preparation and identification. The method used was sample extraction using Barlese Tullgren funnel with several modifications. Samples were taken at 3 vegetation areas (soursop, sarikaya a.k.a Annona squamosa, and sapodilla) and each area was taken five sampling points. The environmental measurements include air humidity and air temperature measured by means of a hygrometer, $\mathrm{pH}$ and soil temperature with digital soil tester, and soil moisture with a soil tester Takemura DM-5. Acarina obtained was seen under a microscope and mounted with Hoyer's solution. The identification of Acarina using identification book A Manual of Acarology. The data obtained from the study were analyzed using the Shannon-Wiener diversity index. Based on Acarina's identification, 20 families and 28 genera and 399 individual numbers were obtained. The level of diversity of Acarina is categorized as the medium category. The environmental factors that influence the presence of Acarina are temperature and humidity.
\end{abstract}

Keywords: Acarina, Barlese Tullgren, Shannon-Wiener 


\section{PENDAHULUAN}

Acarina oleh masyarakat umum lebih dikenal dengan mites atau ticks. Subclass Acari terdistribusi di seluruh dunia dan lebih dari 55.000 spesies terdeskripsi. Habitat Acarina yaitu hidup di darat, air tawar, bahkan air laut dan dari gurun sampai es (Wall \& Shearer, 2001, p. 23). Acarina terestrial biasanya hidup di tanah, serasah, daun, ataupun kulit pohon. Peran Acarina dipengaruhi oleh kebiasaan makan dan habitatnya. Acarina memiliki dua bentuk kehidupan yang utama yaitu Acarina yang hidup bebas dan parasit. Spesies pada kedua kelompok tersebut bisa bermanfaat dan bisa merugikan. Acarina yang bermanfaat misalnya yang berperan sebagai predator yang bisa digunakan untuk pengendalian hayati hama. Acarina yang merugikan misalnya sebagai hama dan parasit. Acarina yang bersifat parasit terbagi menjadi ektoparasit (hidup di luar tubuh vertebrata/ invertebrata) dan endoparasit (hidup di dalam tubuh vertebrata/invertebrata) (Krantz, 1978; Navajas et al., 2010). Acarina dimasukkan dalam phylum Arthropoda, subphylum Chelicerata, class Arachnida, orde Acariformes dan Parasitiformes (Hoy, 2011, p. 10). Acarina tanah terbagi menjadi empat suborder yaitu Cryptostigmata, Mesostigmata, Prostigmata, dan Astigmata (Borah \& Kakati, 2014; Tsurho \& Ao, 2014). Acarina tanah berperan penting dalam kesuburan tanah melalui dekomposisi materi organik, mineralisasi tanah, memelihara struktur fisik tanah, daur nutrien, aliran energi, dan meningkatkan produktivitas primer.

Kebun Pendidikan Penelitian dan Pengembangan Pertanian Universitas Gadjah Mada (KP4 UGM) Yogyakarta yang didirikan pada tahun 1975 sekarang bernama Pusat Inovasi Agro Teknologi (PIAT). PIAT tersusun atas dua bidang yaitu Bidang Pengelolaan Sumber Daya Pangan Pangan Berkelanjutan dan Bidang Konservasi Sumber Daya Alam Berkelanjutan. Kedua bidang tersebut masing-masing didukung oleh subbidang-subbidang lainnya. PIAT Mangunan merupakan salah satu Subbidang Perkebunan dan Biofarmaka dengan luas sekitar 153 hektar dan ditanami pohon buah seperti sawo, sirsak, srikaya, alpukat, tanaman kayu, dan tanaman herbal. Produktivitas tanaman buah tidak terlepas dari hama dan fauna tanah. Fauna tanah dalam penelitian ini salah satunya adalah Acarina. Acarina yang hidup di tanah mencapai ratusan sampai ribuan per $\mathrm{m}^{2}$. Acarina tanah ditemukan sampai kedalaman 10 $\mathrm{m}$ mengikuti sistem perakaran tumbuhan (Coddington \& Colwell, 2001).

PIAT sebagai fasilitas penelitian lebih banyak digunakan dalam penelitian mengenai tumbuhan atau flora. Penelitian yang dilakukan oleh Firmansyah (2014) 
mengenai Arthropoda tanah dalam lahan monokultur Zea mays L. di KP4 UGM ditemukan Acarina dengan family Laelapidae, dan Suborder Oribatidae, dan springtails (Hypogasturidae). Penelitian oleh Utomo, Prihatin, dan Asyiah (2019) mengenai mesofauna tanah pada lahan tanaman kopi arabika di Perkebunan Kalibendo Banyuwangi diperoleh spesiesdari order Collembola dan Acarina yang didapat yaitu Ixodidae. Penelitian oleh Munarsih, Rahadian, dan Hadi (2014) mengenai struktur komunitas mikroarthropoda bryofauna terestrial di Zona Tropik Gunung Ungaran, Semarang, Jawa Tengah diperoleh Acarina berupa Mesostigmata dan Oribatida. Penelitian mengenai fauna tanah khususnya Acarina di PIAT Mangunan belum dikaji sehingga penelitian ini dilakukan. Penelitian ini bertujuan untuk mengetahui keanekaragaman Acarina dan faktor lingkungan yang mempengaruhi Acarina di PIAT Mangunan. Manfaat penelitian ini sebagai data inventarisasi Acarina di PIAT Mangunan.

\section{METODE PENELITIAN}

Penelitian ini dilakukan di PIAT Mangunan yang terletak di Jalan ImogiriDlingo Km. 2, Banyusumurup, Girirejo, Imogiri, Bantul, Yogyakarta untuk pengambilan sampel dan Laboratorium Sistematika Hewan bagian Parasitologi Fakultas Biologi
UGM untuk preparasi dan identifikasi. Metode yang digunakan adalah ekstraksi sampel menggunakan corong Barlese Tullgren (Andres \& Mateos, 2006) dengan beberapa modifikasi. Sampel diambil pada 3 area vegetasi (sirsak, srikaya, dan sawo) dan setiap area diambil lima titik sampling. Sampel tanah diambil menggunakan cetok kira-kira sebanyak 50 gram dan serasah kirakira 20 gram kemudian dimasukkan dalam plastik bening dan diberi label. Pengukuran lingkungan meliputi kelembaban udara dan suhu udara diukur dengan alat higrometer, $\mathrm{pH}$ dan suhu tanah dengan soil tester digital, serta kelembaban tanah dengan soil tester Takemura DM-5.

Sampel tanah dan serasah dari PIAT Mangunan dibawa ke Laboratorium Sistematika Hewan bagian Parasitologi Fakultas Biologi UGM dan diletakkan dalam Barlese Tullgren dengan panas lampu 25 watt dan ditampung dalam botol yang berisi alkohol $70 \%$. Setelah 48 jam, botol tersebut dituang di cawan petri untuk disortir Acarinanya. Acarina yang diperoleh dilihat di bawah mikroskop dan dimounting dengan larutan hoyer's. Preparat yang akan digunakan dalam jangka waktu yang lama bisa diseal dengan kuteks bening. Identifikasi Acarina menggunakan buku identifikasi A Manual of Acarology (Krantz, 1978).

Data yang diperoleh dari penelitian dianalisis menggunakan indeks keaneka- 
ragaman Shannon-Wiener (Krebs, 1978) dengan rumus:

$$
H^{\prime}=\sum_{i=n}^{n} P i 1 n P i
$$

Keterangan:

$$
\begin{aligned}
H^{\prime}= & \text { Indeks keanekaragaman Shannon } \\
& \text { Wiener } \\
n= & \text { Jumlah spesies } \\
P i= & \text { Proporsi jumlah individu jenis ke-1 } \\
& \text { dengan jumlah individu total contoh }
\end{aligned}
$$

Kisaran nilai tolak ukur indeks keanekaragaman sebagai berikut:

$$
\begin{array}{ll}
\mathrm{H}<1,0 & =\text { Keanekaragaman rendah } \\
1,0<\mathrm{H}<3,22 & =\text { Keanekaragaman sedang } \\
\mathrm{H}>3,22 & =\text { Keanekaragaman tinggi }
\end{array}
$$

\section{HASIL DAN PEMBAHASAN}

Acarina bersifat kosmopolit yang persebarannya luas dan dapat ditemui dari berbagai macam habitat, dapat hidup bebas di tanah, fitofagus, dan sebagai ektoparasit. Penelitian ini bertujuan untuk mengetahui jenis dan peran Acarina di Pusat Inovasi Agro Teknologi (PIAT) Mangunan. Berdasarkan identifikasi Acarina yang telah dilakukan, didapatkan 20 Family dan 28 Genus. Acarina yang ditemukan seluruhnya berjumlah 399 cacah individu (Tabel 1). Jumlah Acarina sebanyak 399 berasal dari penjumlahan Acarina yang diperoleh dari 3 area sampling di PIAT Mangunan. Acarina yang ditemukan di area A dengan vegetasi sirsak sebanyak 121. Area B dengan vegetasi srikaya ditemukan Acarina sebanyak 126.
Acarina di area $\mathrm{C}$ dengan vegetasi sawo ditemukan sebanyak 152 .

Berdasarkan Tabel 1, Acarina yang paling banyak ditemukan di area A dan C adalah genus Scheloribates, dan Acarina yang paling banyak ditemukan di area B adalah genus Hafenrefferia. Genus yang ditemukan di area A lebih banyak meskipun jumlah cacah individu yang ditemukan lebih sedikit daripada kedua area yang lain dan di area $\mathrm{C}$ ditemukan jumlah cacah individu yang lebih banyak meskipun genus yang didapat tidak sebanyak di area A. Perbedaan genus pada area tersebut dikarenakan mungkin ada Acarina yang hanya mampu beradaptasi di area tertentu dan tidak cocok di area lain untuk menunjang kelangsungan hidupnya, misalnya genus Lohmannia, Cryptognathus, Armascirus, dan Stenotarsonemus hanya ditemukan di area A dan genus Macrocheles hanya ditemukan di area C. Selain itu, area dengan vegetasi sawo (C) memiliki percabangan horizontal dengan daun yang rimbun sehingga Acarina terlindung oleh kanopi, di area ini juga ditemukan Unguizetes (sebagai dekomposer) yang lebih banyak daripada di kedua area sehingga unsur hara di dalam tanah lebih banyak dan Acarina yang ditemukan juga lebih banyak.

Pada umumnya, keberlimpahan Acarina dipengaruhi oleh hasil interaksi dari lingkungannya seperti faktor abiotik, misalnya suhu, kelembaban, dan $\mathrm{pH}$. Tabel 
Jurnal Penelitian Saintek, Vol. 25, Nomor 1, 2020

Tabel 1

Acarina di Pusat Inovasi Agro Teknologi (PIAT) Mangunan

\begin{tabular}{|c|c|c|c|c|c|c|}
\hline \multirow{2}{*}{ Order } & \multirow{2}{*}{ Suborder } & \multirow{2}{*}{ Family } & \multirow{2}{*}{ Genus } & \multicolumn{3}{|c|}{ Total } \\
\hline & & & & $\overline{\mathrm{A}}$ & $\mathrm{B}$ & $\mathrm{C}$ \\
\hline \multirow{25}{*}{ Acariformes } & Astigmata & Acaridae & Acarus & 10 & 14 & 18 \\
\hline & & & Tyrophagus & 1 & 1 & 0 \\
\hline & Oribatida & Belbidae & Damaeus & 3 & 3 & 2 \\
\hline & & Galumnidae & Galumna & 8 & 8 & 5 \\
\hline & & Haplozetidae & Peloribates & 3 & 0 & 1 \\
\hline & & & Rostrozetes & 6 & 2 & 0 \\
\hline & & Liacaridae & Hafenrefferia & 14 & 25 & 20 \\
\hline & & Lohmanniidae & Lohmannia & 1 & 0 & 0 \\
\hline & & Mochlozetidae & Unguizetes & 7 & 16 & 29 \\
\hline & & Perlohmanniidae & Perlohmannia & 0 & 2 & 2 \\
\hline & & Scheloribatidae & Ischeloribates & 8 & 14 & 16 \\
\hline & & & Scheloribates & 17 & 21 & 33 \\
\hline & Prostigmata & Anystidae & Bechsteinia & 7 & 0 & 6 \\
\hline & & Cheyletidae & Cheyletus & 2 & 2 & 0 \\
\hline & & Cryptognathidae & Cryptognathus & 1 & 0 & 0 \\
\hline & & Cunaxidae & Armascirus & 1 & 0 & 0 \\
\hline & & & Cunaxa & 2 & 3 & 2 \\
\hline & & & Neobonzia & 2 & 0 & 2 \\
\hline & & & Pulaeus & 4 & 0 & 1 \\
\hline & & Erythraeidae & Balaustium & 3 & 3 & 0 \\
\hline & & & Erythacarus & 2 & 0 & 1 \\
\hline & & & Leptus & 0 & 1 & 1 \\
\hline & & Paratydeidae & Paratydeus & 1 & 2 & 0 \\
\hline & & Tarsonemidae & Stenotarsonemus & 1 & 0 & 0 \\
\hline & & Tenuipalpidae & Brevipalpus & 6 & 4 & 8 \\
\hline \multirow[t]{3}{*}{ Parasitiformes } & Mesostigmata & Macrochelidae & Macrocheles & 0 & 0 & 1 \\
\hline & & Phytoseiidae & Amblyseius & 10 & 3 & 2 \\
\hline & & Uropodidae & Urodiaspis & 1 & 2 & 2 \\
\hline
\end{tabular}

2 menyajikan data pengukuran parameter lingkungan yang dilakukan dalam penelitian.

Collof (2009) menjelaskan bahwa temperatur yang tinggi mempercepat reaksi metabolisme sehingga perkembangan dan reproduksi selesai dalam waktu yang lebih singkat. Temperatur yang optimum untuk Acarina adalah $25-30^{\circ} \mathrm{C}$. Berdasarkan Tabel 2, suhu tanah pada area A berada di kisaran optimum dan di area B dan $\mathrm{C}$ sedikit di atas 
Keanekaragaman Acarina (Poerwanto, S. H., Handiani, A., \& Windyaraini, D. H.)

Tabel 2

Hasil Pengukuran Parameter Lingkungan

\begin{tabular}{clccc}
\hline \multirow{2}{*}{ No } & $\begin{array}{c}\text { Parameter } \\
\text { Lingkungan }\end{array}$ & $\begin{array}{c}\text { Area } \\
\text { Sampel }\end{array}$ & $\begin{array}{c}\text { Nilai } \\
\text { Optimum }\end{array}$ & $\begin{array}{c}\text { Nilai } \\
\text { Terukur }\end{array}$ \\
\hline 1 & Suhu tanah & A & $25-30$ & $29,7 \pm 3,9$ \\
& $\left({ }^{\circ} \mathrm{C}\right)$ & B & & $31 \pm 4,9$ \\
& & C & & $31,5 \pm 2$ \\
2 & Kelembaban & A & $40-80$ & $58,7 \pm 6,4$ \\
& tanah $(\%)$ & B & & $60 \pm 8,9$ \\
\multirow{2}{*}{3} & pH tanah & C & & $60,3 \pm 4,8$ \\
& & A & 6,2 & $5,6 \pm 0,9$ \\
& & B & & $5,3 \pm 1,1$ \\
\multirow{2}{*}{4} & Suhu udara & C & & $5,6 \pm 0,9$ \\
& ( ${ }^{\circ}$ C) & B & $25-30$ & $33,4 \pm 3,4$ \\
& & C & & $37,6 \pm 3,3$ \\
\multirow{2}{*}{5} & Kelembaban & A & $40-80$ & $46,4 \pm 6,7$ \\
& udara $(\%)$ & B & & $38,4 \pm 3,8$ \\
& & C & & $45 \pm 3,2$ \\
\hline
\end{tabular}

nilai optimum, suhu udara di ketiga area lebih dari nilai optimum dan paling tinggi di area B. Suhu udara yang tinggi di area B membuat kelembaban udaranya juga berada di bawah nilai optimum. Area B terdapat vegetasi srikaya yang daun dan buahnya banyak yang kering sehingga Acarina tidak terlindungi kanopi dan akumulasi serasahnya juga sedikit. Kelembaban berpengaruh pada Acarina yang berperan sebagai fungivor (pemakan fungi). Kelembaban yang optimum untuk Acarina yaitu 40-80\%. Unsur hara di dalam tanah sedikit sebagai akibat dari $\mathrm{pH}$ yang terukur di bawah nilai optimum dan $\mathrm{pH}$ yang terlalu rendah, serta $\mathrm{pH}$ yang terlalu tinggi tidak disukai Acarina.
$\mathrm{pH}$ tanah yang optimum untuk Acarina yaitu 6,2 (Khabir, Nejad, Moghaddam, Khanjani, \& Zargaran, 2014). Hasil pengukuran parameter lingkungan yang berada di bawah atau di atas nilai optimum masih bisa ditoleransi oleh Acarina sehingga di ketiga area terdapat Acarina. Faktor lingkungan yang paling mempengaruhi keberadaan Acarina di PIAT yaitu suhu dan kelembaban. Acarina memiliki berbagai macam peran di dalam suatu habitat. Beragamnya peran tersebut disebabkan perbedaan cara makan dan sumber nutrisi yang diperlukan Acarina. Berikut ini merupakan peran utama Acarina yang ditemukan di PIAT Mangunan. 
Pada Gambar 1, peran Acarina berdasarkan pada genus yang ditemukan dalam tanah dan serasah di Pusat Inovasi Agro Teknologi (PIAT) Mangunan adalah fitofagus, graminivor, fungivor, detritivor, panfitofagus, makrofitofagus, predator, dan dekomposer. Acarina yang berperan sebagai fitofagus memakan zat atau material tumbuhan dan menjadi hama pada pohon yang berbuah. Acarina yang berperan sebagai fitofagus yaitu Acarus (Krantz, 1978), Tyrophagus (Fang \& Zhang, 2007), Cryptognathus (Khanjani, Khanjani, NajavAbadi, \& Seeman, 2014), Stenotarsonemus (Baker \& Wharton, 1952) dan Brevipalpus (Vacante, 2010). Acarina yang berperan sebagai graminivor memakan biji-bijian yaitu Acarus (Robinson, 2005). Acarina yang berperan sebagai fungivor memakan fungi. Acarina yang termasuk fungivor yaitu Tyrophagus (Fang \& Zhang, 2007) dan Unguizetes (Ermilov \& Kaluz, 2012). Acarina yang berperan sebagai detritivor memakan detritus (bagian tumbuhan dan hewan yang membusuk, serta kotoran). Acarina yang berperan sebagai detritivor yaitu Damaeus (Krantz, 1978), Ischeloribates (Mahunka, 1986) dan Balaustium (Krantz, 1978). Acarina yang berperan sebagai panfitofagus memakan zat atau material tumbuhan dan fungi. Acarina yang berperan sebagai panfitofagus yaitu Galumna (Culliney, 2013) dan Hafenrefferia (Glime, 2017). Acarina yang berperan sebagai makrofitofagus memakan tumbuhan yang sudah membusuk, terkadang fungi. Acarina

Gambar 1. Peran Acarina di PIAT Mangunan

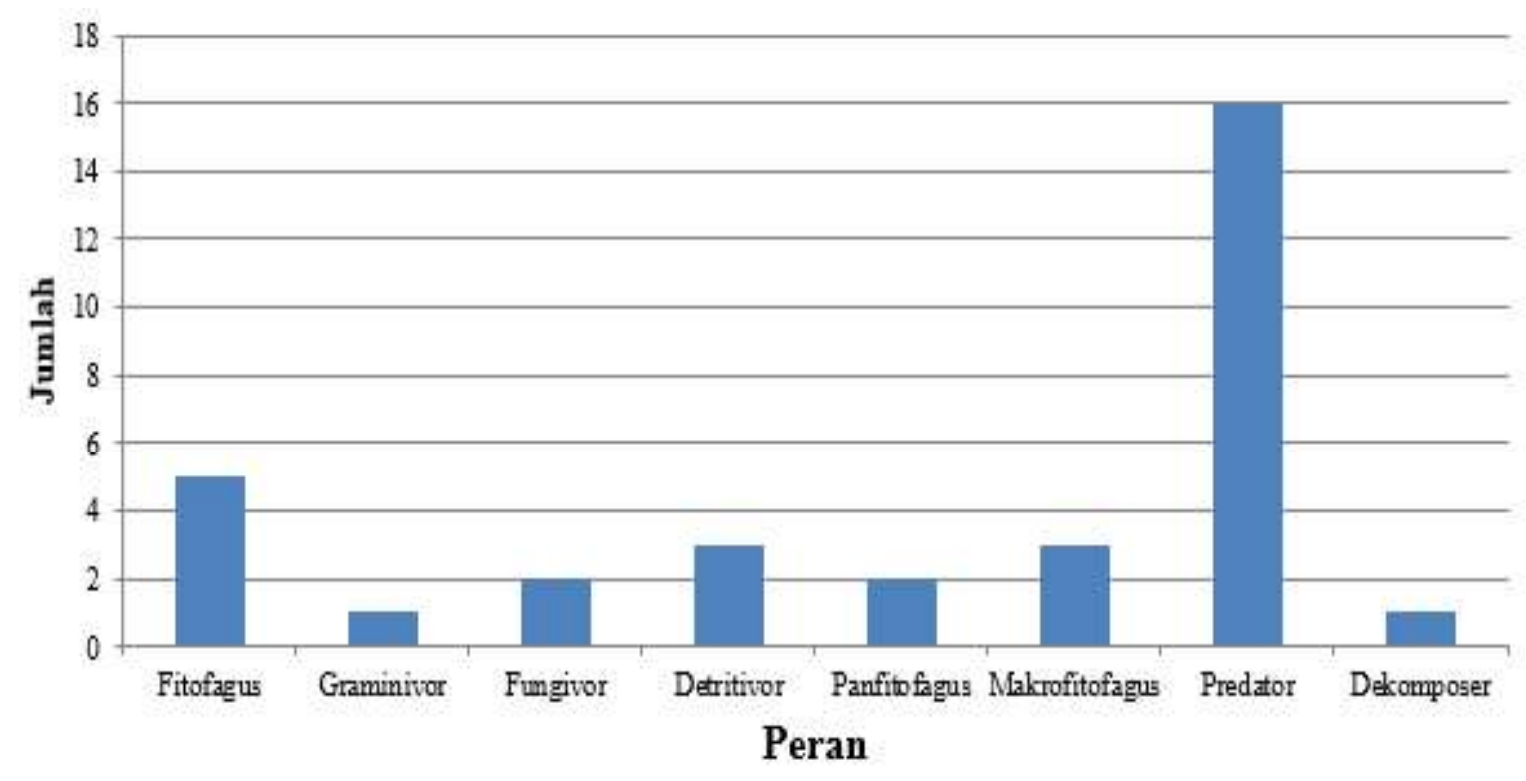


sebagai makrofitofagus yaitu Galumna (Culliney, 2013), Lohmannia (Krantz, 1978), dan Perlohmannia (Mortazavi, Akrami, \& Hajizadeh, 2016). Acarina sebagai predator merupakan peran yang paling tinggi di antara peran yang lain, hal ini disebabkan tersedianya makanan yang cukup untuk Acarina predator berupa arthropoda kecil, nematoda, collembola, Acarina lain dan sebagainya. Acarina yang berperan sebagai predator yaitu Peloribates (Krantz, 1978), Rostrozetes (Krantz, 1978), Ischeloribates (Mahunka, 1986), Scheloribates (Krantz, 1978), Bechsteinia (Krantz, 1978), Cheyletus (Krantz, 1978), Armascirus (Skvarla, Fisher, \& Dowling, 2014), Cunaxa (Skvarla et al., 2014), Neobonzia (Chen, Guo, Yi, \& Jin, 2018), Pulaeus (Skvarla et al., 2014), Erythacarus (Baker \& Wharton, 1952), Leptus (Bernard, Felska, \& Makol, 2019), Paratydeus (Khaustov, 2017), Macrocheles (Ozbek, Bal, \& Dogan, 2015), Amblyseius (Krantz, 1978), dan Urodiaspis (Baker \& Wharton, 1952). Acarina yang berperan sebagai dekomposer membantu dekomposisi bahan organik dan pengurai yaitu Unguizetes (Ermilov \& Kaluz, 2012).
Acarina yang memiliki peran ganda ada lima genus yaitu Acarus, Tyrophagus, Unguizetes, Ischeloribates, dan Galumna. Peran Acarina yang diperoleh secara tidak langsung dapat merugikan dan menguntungkan pada produktivitas pohon yang ditanam di PIAT Mangunan terutama pohon sirsak, srikaya, dan sawo. Acarina sebagai fitofagus menjadi hama yang menyeranga tanaman dan adanya Acarina sebagai predator sebagai pengendali hayati fitofagus. Selain itu, adanya Unguizetes membantu dekomposisi dan pengurai sehingga unsur hara yang terkandung di dalam tanah lebih subur dan berpengaruh pada produktivitas tanam.

Keanekaragaman Acarina ditentukan dengan menggunakan rumus indeks keanekaragaman Shannon-Wiener. Data pada Tabel 3 merupakan hasil penghitungan indeks Shannon-Wiener di Pusat Inovasi Agro Teknologi (PIAT) Mangunan.

Indeks keanekaragaman ShannonWiener bertujuan untuk mengetahui tingkat keanekaragaman rata-rata spesies di PIAT. Tabel 3 menunjukkan bahwa ketiga area memiliki indeks keanekaragaman Acarina dengan kategori sedang. Indeks

Tabel 3

Indeks Keanekaragaman Acarina di PIAT Mangunan

\begin{tabular}{cccc}
\hline Area & $\mathrm{H}^{\prime}$ & Nilai Tolak Ukur & Kategori \\
\hline A & 2.860617676 & $1<\mathrm{H}^{\prime}<3.22$ & Keanekaragaman Sedang \\
B & 2.415984918 & $1<\mathrm{H}^{\prime}<3.22$ & Keanekaragaman Sedang \\
C & 2.306182296 & $1<\mathrm{H}^{\prime}<3.22$ & Keanekaragaman Sedang \\
\hline
\end{tabular}


tersebut menunjukkan pada Pusat Inovasi Agro Teknologi, Acarina dapat hidup dan bereproduksi dengan cukup baik, yang dipengaruhi parameter lingkungan dan ketersediaan sunber makanan atau nutrisi yang cukup bagi Acarina, kondisi ekosistem cukup seimbang, dan tekanan ekologisnya sedang. Kondisi ekosistem yang seimbang dikarenakan tidak adanya gangguan sehingga ekosistem mampu mempertahankan keadaannya.

\section{SIMPULAN}

Acarina yang ditemukan di PIAT Mangunan Universitas Gadjah Mada Yogyakarta sebanyak 399 cacah individu yang terdiri dari 28 genus dan 20 family, yaitu famili Acaridae, Belbidae, Galumnidae, Haplozetidae, Liacaridae, Lohmanniidae, Mochlozetidae, Perlohmanniidae, Scheloribatidae, Anystidae, Cheyletidae, Crytognathidae, Cunaxidae, Erythraeidae, Paratydeidae, Tarsonemidae, Tenuipalpidae, Macrochelidae, Phytoseiidae, dan Uropodidae. Tingkat keanekaragaman Acarina termasuk dalam kategori sedang. Faktor lingkungan yang mempengaruhi kehadiran Acarina adalah suhu dan kelembaban.

\section{DAFTAR PUSTAKA}

Andres, P., \& Mateos, E. (2006). Soil mesofaunal responses to post-mining restoration treatments. Applied Soil Ecology, 33, 67-78.
Baker, E. W., \& Wharton, G. W. (1952). An introduction to acarology. New York: The Macmillan Company.

Bernard, R., Felska, M., \& Makol, J. (2019). Erythraeid larvae parasitizing Dragonflies in Zambia-description of Leptus (Leptus) chingombensis sp. nov. with data on biology and ecology of host-parasite interactions. Systematic \& Applied Acarology, 24(5), 790-813.

Borah, M., \& Kakati, L. N. (2014). Population dynamics of soil Acarina in natural and degradated forest ecosystem at Pathalipam, Lakhimpur, Assam. IOSR Journal of Environmental Science, Toxicology, and Food Technology (IOSR-JESTFT), 8(1), 45-50.

Chen, J. X., Guo, J. J., Yi, T. C., \& Jin, D. C. (2018). A new species of Neobonzia (Acariformes: Cunaxidae, Coleoscirinae) with a key to species of China. Systematic \& Applied Acarology, 23(1), 104-112.

Coddington, J. A., \& Colwell, R. K. (2001). Arachnids. Academic Press. Encyclopedia of Biodiversity, 1, 199218.

Collof, M. J. (2009). Dust mites. Australia: CSIRO Publishing.

Culliney, T. W. (2013). Role of Arthropods in maintaining soil fertility. Agriculture, 3, 629-659.

Ermilov, S. G., \& Kaluz, S. (2012). A species of the Genus Unguizetes (Acari: Oribatida: Mochlozetidae) from Ecuador. Acarina, 20(2), 180-184.

Fang, Q. H., \& Zhang, Z. Q. (2007). Tyrophagus (Acari: Astigmata: Acaridae). Fauna of New Zealand, 56.

Firmansyah, R. B. (2014). Keragaman dan kemelimpahan Arthropoda tanah di lahan monokultur (Zea mays L.) Kebun Pendidikan, Penelitian dan Pengembangan Pertanian UGM (KP4 
UGM) (Skripsi). Fakultas Biologi, Universitas Gadjah Mada, Yogyakarta.

Glime, J. M. (2017). Arthropods: Mites (Acari) (Chapt 9-1). Dalam J. M. Glime (2010), Bryophyte ecology (vol. 2). Bryological Interaction.

Hoy, M. A. (2011). Agricultural Acarology: Introduction to Integrated Mite Management (p. 10). New York: CRC Press, Taylor and Francis Group, LLC.

Khabir, Z. H., Nejad, K. H. I., Moghaddam, M., Khanjani, M., \& Zargaran, M. R. (2014). Species richness of oribatid Mites (Acari: Oribatida) in range lands of West Azerbaijan Province, Iran. Persian Journal of Acarology, 3(4), 293-309.

Khanjani, M., Khanjani, M., Najav-Abadi, P. R., \& Seeman, O. D. (2014). Three new species of the genus favognathus luxton (Acari: Cryptognathidae) and re-description of cryptognathus lagena kramer from India. International Journal of Acarology, 40(5), 370-383.

Khaustov, A. A. (2017). Review of the paratydeidae (Acari: Prostigmata), with description of the three new species. Zootaxa, 4303(2), 151-212.

Krantz, G. W. (1978). A manual of acarology $\left(2^{\text {nd }}\right.$ ed.). Corvallis: Oregon State University Book Stores, Inc.

Krebs, C. J. (1978). Ecological methodology. New York: Harper and Row Publisher.

Mahunka, S. (1986). Oribatids from Africa (Acari, Oribatida) IV. Annales Historico-Naturales Musei Nationalis Hungarici, 78, 301-317.

Mortazavi, S., Akrami, M. A., \& Hajizadeh, J. (2016). Redescription of perlohmannia (Perlohmannia) dissimilis (Acari, Cryptostigmata, Perlohmaniidae) collected from Guilan Province Iran. Linzer biol. Beitr., 48(1), 693-703.

Munarsih, A., Rahadian, R., \& Hadi, M. (2014). Struktur komunitas mikro- artropoda bryofauna terestrial di zona tropik Gunung Ungaran, Semarang, Jawa Tengah. BIOMA, 16(1), 50-57.

Navajas, M., Migeon, A., Estrada-Pena, A., Mailleux, A. C., Servigne, P., \& Petanovic, R. (2010). Mites and ticks (Acari) Chapter 7.4. BioRisk, 4(1), 149192.

Ozbek, H. H., Bal, D. A., \& Dogan, S. (2015). The genus macrocheles latreille (Acari: Mesostigmata: Macrochelidae) from Kelkit Valley (Turkey), with three newly recorded mite species. Turkish Journal of Zoology, 39, 768-780.

Robinson, W. H. (2005). Handbook of urban insects and arachnids. Cambridge, UK: Cambridge University Press.

Skvarla, M. J., Fisher, J. R., \& Dowling, A. P. G. (2014). A review of cunaxidae (Acariformes, Trombidiformes): Histories and diagnoses of subfamilies and genera, keys to world species, and some new locality records. Zookeys, 418, $1-103$.

Tsurho, K., \& Ao, B. (2014). Ventral distribution and abundance of soil acarina in a natural forest and jhum land ecosystem of Mokokchung, Nagaland. International Journal of Science, Engineering and Technology, 2(5), 371391.

Utomo, F. I., Prihatin, J., \& Asyiah, I. N. (2019). Identifikasi mesofauna tanah pada lahan tanaman kopi arabika di perkebunan Kalibendo Banyuwangi. Saintifika, 21(1), 39-51.

Vacante, V. (2010). Citrus mites: Identification, bionomy, and control. CAB International. UK: Oxford.

Wall, R. \& Shearer. (2001). Veterinary ectoparasites: Biology, pathology, and control ( $2^{\text {nd }}$ ed.). Oxford, London: Blackwell Science Ltd. 